\title{
Malformaciones obstructivas congénitas de los genitales femeninos. 5 casos clínicos
}

DRS. FRANCISCO OSSANDON CORREA*, ALFREDO DEL RIO MARTINEZ* y CESAR IZZO SANDER*

El hidrocolpos y la hematometra son 2 entidades bien conocidas en su etiopatogenia. Todos hemos escuchado hablar del himen imperforado y sus consecuencias en la pubertad. Sin embargo para muchos de nosotros es nuevo el alcance que tienen, estas y otras obstrucciones del canal vaginal en el recién nacido y lactante menor. Es aquí donde aparecen una serie de signos y síntomas, que suelen desviar el diagnóstico preciso, cuando no se piensa en él, o no se ha tenido alguna experiencia clínica anterior.

MATERIAL.- En el Servicio de Cirugía Infantil del Hospital Luis Calvo Mackenna, hemos observado 5 casos en los últimos 4 años; 3 en recién nacidos y 2 en niñas púberes.

En el recién nacido se observaron varias formas clínicas (Fig. 1). En el 1. ${ }^{\text {er }}$ caso, en el examen de rutina, la enferma presentaba una imperforación del himen con una masa amarillenta que protruía con el llanto ("Bulging vagina"). Se puncionó el himen $\mathrm{y}$ se introdujo Hypaque al $10 \%$, encontrando vagina dilatada a Rayos X.

En el $2^{\circ}$ caso, la paciente consultó a los 36 días de edad por distensión abdominal y aumento de volumen, con coloración azulada de extremidad inferior izquierda. En el examen se palpó masa con caracteres de vejiga. Se pasó sonda uretral, obteniendo $270 \mathrm{cc}$. de orina, cediendo el cuadro agudo. El examen genital externo era normal. El cuadro se reprodujo a las 4 horas después de haber retirado la sonda vesical. En un nuevo sondeo se obtuvo gran cantidad de orina y con vejiga vacía se palpó masa redondeada, dura, hipogástrica. Se practicó pielografía que demostró rechazo anterior de vejiga y lateral de uréteres con hidroureteronefrosis bilateral.

Un 3. ${ }^{\text {er }}$ caso ingresó al Servicio de Prematuros por imperforación anal. En el examen abdominal

\footnotetext{
- Servicio de Cirugía Infantil, Hospital Luis Calvo Mackenna.
}

se palpó masa hipogástrica que no desapareció al vaciar vejiga. El examen genital demostró un solo orificio vulvar que correspondía a uretra.

Los casos 1 y 3 se operaron por vía abdominal, encontrándose gran hidrocolpos y rechazo del útero, con dilatación de él. Se abrió vagina en el fondo del saco, vaciando abundante líquido amarillento. Se introdujo una Kelly por la vaginotomía, haciendo protruir, en el caso 1 , un tabique vaginal transversal (diafragma) por la vulva, el que se resecó y se dejó drenaje vaginal por vulva. (Fig. 2).

En el caso 2 se practicó una exéresis del himen, obteniendo gran cantidad de líquido.

Los enfermos 1 y 2 evolucionaron bien, sin complicaciones. La tercera enferma falleció en el post operatorio precoz, por una depresión respiratoria, probablemente anestésica.

Los casos 4 y 5 se presentaron en niñas de 11 y 12 años de edad, respectivamente. La enferma № 4 presentaba crisis cólicas abdominales bajas y una masa hipogástrica, que motivaron su intervención de urgencia, con el diagnóstico de quiste ovárico torcido. Llevaba un mes de tratamiento con el diagnóstico de infección urinaria, pero el urocultivo reveló sólo $30.000 \mathrm{col}$. de E. Coli. En la operación se encontró un hematocolpos y hematometra. Se drenó por colpotomía, en el fondo de saco vaginal. Se cerró la colpotomía sin drenajes y se derivó la enferma a Ginecología. El examen genital demostró un cordón atrésico que reemplazaba vagina en su mitad distal.

E] caso No 5 consultó por cólicos abdominales periódicos y masa hipogástrica dura que llegaba hasta el ombligo. Inicialmente se pensó en embarazo, pero los "pregnosticones" fueron negativos. Luego se pidió pielografía que demostró una masa abdominal redondeada, central, baja, con dilatación y rechazo lateral de uréteres. Se derivó la enferma a nuestro Servicio, donde com- 


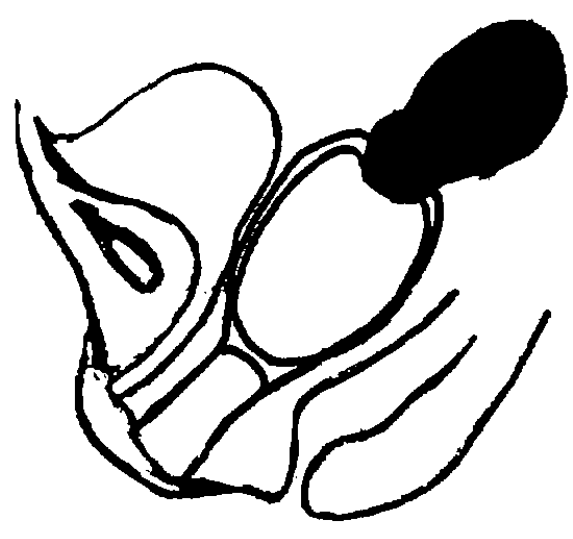

DIAFRAGMA

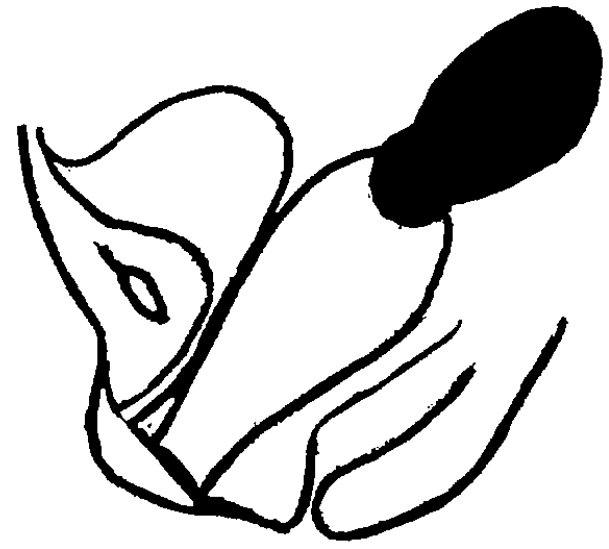

HIMEN IMPERFORADO

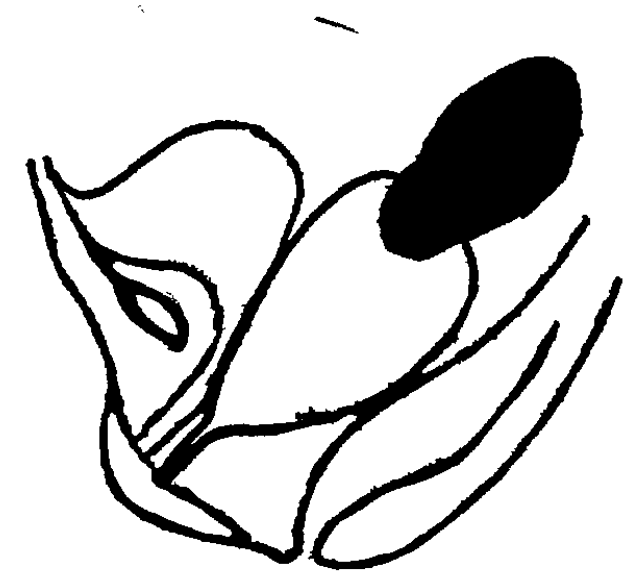

ATRESIA CORDONAL

FIGURA No 1.

probamos un himen imperforado y grueso, con aspecto de piel. Se puncionó el himen, obteniendo $1.500 \mathrm{cc}$. de sangre negruzca. Se resecó el tabique himenal.

Ambas enfermas han evolucionado bien, practicándose vaginoplastía, a la primera de ellas, en el Servicio de Ginecología.

DISCUSION.- Según Smith en EE.UU., entre los años 1940 y 1971 se habían comunicado 79 casos de hidrocolpos. El $85 \%$ se presenta en menores de 10 meses. La mortalidad global es superior al $50 \%$, con una alta mortalidad operatoria. Ello se atribuye a falta de diagnóstico pre operatorio, que condiciona una mala cirugía, con exéresis de útero, trompas y, a veces, ovario. Tuegan un papel en la alta mortalidad las malformaciones asociadas. En 48 casos, entre 1940 y 1964, se hizo el diagnóstico preoperatorio correcto en 26 ; en 16 casos se hizo laparotomía exploradora $(33 \%)$ con 8 histerectomías innecesarias, $\mathrm{y}$ en 6 casos el diagnóstico se hizo por autopsia.

Spence, en una revisión de 40 casos, en 1962, encontró que en el $50 \%$, el único síntoma era una masa abdominal media infraumbilical, que no desaparecía al vaciar la vejiga. En el $35 \%$ de los casos hubo poliaquiuria y posteriormente, episodios de náuseas y vómitos, y en 2 casos, dificultad respiratoria por ascenso diafragmático.

La retención urinaria aguda se explica por el desplazamiento anterior de vejiga, con acodamiento de uretra. Este síntoma en el recién nacido, nos obliga a hacer el diagnóstico diferencial con Ureterocele ectópico obstructivo. En todos estos casos hay una hidronefrosis e hidrouretes bilateral, secundarios al obstáculo mecánico, que mejoran al tratar el hidrocolpos.

Un conjunto de síntomas importantes son los determinados por la estasia venosa pélvica, con cianosis y edema de las extremidades. En nuestro primer caso y lo hemos observado también en casos de ureterocele obstructivo, al vaciar vejiga desaparece la cianosis y regresa el edema, pues, tanto la enorme vejiga como el hidrocolpos, comprimen la circulación de retorno.

Están descritos en la literatura, sindromes de obstrucción intestinal baja por comprensión intrínseca del recto. 


\section{HIDROCOLPOS POR DIAFRAGMA VAGINAL}

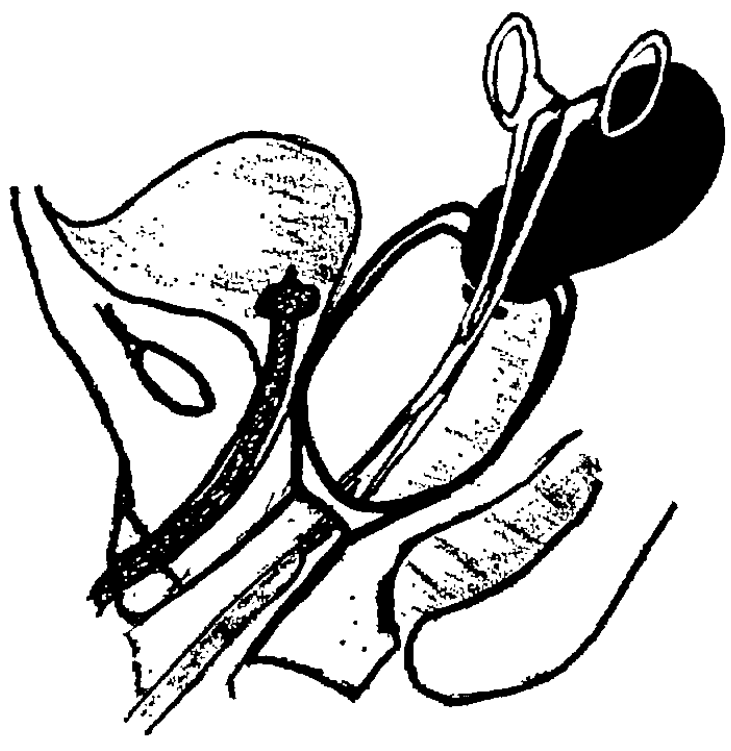

\section{TRAT. QUIRÚRGICO}

Figura No 2.

En la etiopatogenia del hidrocolpos y la hematometra tenemos como causa primaria la obstrucción del canal vaginal. Ello puede deberse a una imperforación de la membrana urogenital, (himen) a una falta de lumenización de los conductos de Muller. Se ha visto, también, obstrucción vaginal en su porción Mulleriana, en relación con el seno urogenital persistente (cloaca) .

Secundariamente a la obstrucción vaginal se acumulan por encima secreciones de origen cervical y endometrial, debidas a la acción estrogénica materna en la recién nacida y propia en la edad puberal. De ahí que la sintomatología que lleva al diagnóstico aparezca en estas edades.

En los exámenes diagnósticos debemos destacar el examen genital externo acucioso y recordar que la presencia de himen normal no excluye una obstrucción más alta. La pielografía descendente, no sólo muestra los signos comentados, sino que permite descartar el riñón doble con ureterocele y nos informa de malformaciones urológicas asociadas, que se ven en el $48 \%$ de los casos, según Smith. De ellas, la más frecuente es la agenesia renal unilatera!. La cistografía demuestra el desplazamiento de vejiga en sentido anterior $\mathrm{y}$ contrasta posibles fístulas vésico vaginales coexistentes. Utiles son también la cistoscopía, el enema baritado y la endoscopía vaginal, que puede revelar una atresia alta.
En en el tratamiento es útil comentar la necesidad de una vía abdomino - perineal en los casos con atresia o diafragmas por encima del himen, para realizar un buen drenaje, y no causar daños mayores. Es importante dejar un drenaje por vía baja (vulvar) y practicar dilataciones post operatorias por meses, en los casos de atresia.

Por último descamos recalcar la necesidad de un adecuado diagnóstico pre operatorio, el que se hace si se piensa en él y no desestimar la mortalidad que acarrea una cirugía apresurada, sin un diagnóstico claro, en el recién nacido.

\section{RESUMEN}

Se presentan 5 casos de malformaciones vaginales obstructivas; 3 en recién nacidas $y$ 2 en niñas de edad puberal.

Se describen los errores diagnósticos y la importancia de una adecuada interpretación de la signo sintomatologia.

Se analiza el tratamiento del hidrocolpos $y$ el hematocolpos con hematometra.

Se resume brevemente algo de la literatura en los últimos 30 años sobre hidrocolpos.

Se recalca la importancia de un buen diagnóstico pre operatorio y de la incidencia de los errores iatrogénicos sobre la morbimortalidad.

\section{SUMMARY}

We present 5 clinical cases of obstructive vaginal malformations, 3 in a new born and 2 in puber girls.

We describe the diagnostic errors, and the importance of an adequate interpretation of signs and symptoms.

We analize the treatment of hydrocolpos; hematocolpos and hematometra.

We summarize briefly some of the literature on hydrocolpos, on the last 30 years.

We stress the importance of a good pre-operative diagnosis, and the incidence over mortality of the diagnostic errors.

\section{REFERENCIAS}

1.-Bowen.- Amer. J. Obs. \& Gynec. 42, 144, 1941.

2.-Gross. - Text Book of Surgery.

3.-Mahoney.- J. Ped. 17, 722, 1940.

4.-Graivier.- J. of Surg. Vol. 4, 5, 1969.

5.- Muangnan.- J. of Urology 106, 1, 1971.

6.-Smith.- J. of Urology 105, 5, 1971.

7.-Mustard.- Pediatric Surg. 2a Edition.

8.- Spence.- Jama 180, 1100, 1962.

9.-Spencer.- Ann. of Surgery 155, 1962. 